\title{
Article \\ Surface Exposure Technology of Metal Powder Based on an Optically-Addressed Liquid Crystal Spatial Light Modulator
}

\author{
Ying Cai ${ }^{1,2}$, Dajie Huang ${ }^{1, *}$,, He Cheng ${ }^{1}$, Gang Xia ${ }^{1}$ and Wei Fan ${ }^{1,2, *}$ \\ 1 National Laboratory on High Power Laser and Physics, Shanghai Institute of Optics and Fine Mechanics, \\ Chinese Academy of Sciences, Shanghai 201800, China; caiying@siom.ac.cn (Y.C.); \\ chenghe@siom.ac.cn (H.C.); xiagang@siom.ac.cn (G.X.) \\ 2 Center of Materials Science and Optoelectronics Engineering, University of Chinese Academy of Sciences, \\ Beijing 100049, China \\ * Correspondence: hdajie@siom.ac.cn (D.H.); fanweil@siom.ac.cn (W.F.)
}

check for updates

Citation: Cai, Y.; Huang, D.; Cheng, H.; Xia, G.; Fan, W. Surface Exposure Technology of Metal Powder Based on an Optically-Addressed Liquid Crystal Spatial Light Modulator. Appl. Sci. 2021, 11, 3647. https://doi.org/ 10.3390/app11083647

Academic Editor: Anming Hu

Received: 2 March 2021

Accepted: 16 April 2021

Published: 18 April 2021

Publisher's Note: MDPI stays neutral with regard to jurisdictional claims in published maps and institutional affiliations.

Copyright: (c) 2021 by the authors. Licensee MDPI, Basel, Switzerland. This article is an open access article distributed under the terms and conditions of the Creative Commons Attribution (CC BY) license (https:/ / creativecommons.org/licenses/by/ $4.0 /)$.
Abstract: Compared with the current mature point scanning metal additive manufacturing technology, the surface exposure technology by laser additive manufacturing can accelerate the construction speed, and the short pulse laser is expected to improve the resolution. Here, a surface exposure technology processing system was constructed based on a nanosecond pulsed laser source and an optically-addressed liquid crystal spatial light modulator with a damage threshold higher than $500 \mathrm{~mJ} / \mathrm{cm}^{2}$. The resolution of the surface exposure processing system is proved to be about $100 \mu \mathrm{m}$.

Keywords: surface exposure; additive manufacturing; amplitude spatial light modulator; pulsed laser; resolution

\section{Introduction}

Metal laser additive manufacturing (AM) is an important technology in the field of three-dimensional (3D) rapid prototyping [1]. It can directly convert a computer-generated 3D model into a physical model and has the advantages of high degrees of freedom [2] and high density [3]. At present, there are many mature metal laser additive manufacturing technologies such as selective laser melting (SLM) [4], selective laser sintering (SLS) [5], and direct energy disposition (DED) [6]. These technologies are based on continuous laser melting and point scanning mode, where the scanning point size is in the order of microns. However, when building a large sample, the processing speed is lower than that of traditional manufacturing technologies.

The manufacturing accuracy of metal powder laser AM is in the range of approximately $80-250 \mu \mathrm{m}$, which is lower than that of stereolithography [6-8]. Therefore, improving the printing accuracy is a crucial research area. It is well known that the thermal diffusion length of a laser is an important factor affecting the forming accuracy. The affected areas are typically composed of a fusion and a heat-affected zone $[9,10]$. The time scale of the continuous laser is large, hence, it has a higher temperature and longer diffusion length compared to the pulsed laser, resulting in a larger heat-affected zone [11], which has a strong effect on the resolution. Therefore, a technology of surface exposure (SE) additive manufacturing of metal powder with short pulses is expected to improve the construction rate and resolution. Matthews reported a new AM method based on diodes and layer-by-layer printing by coupling the light valve with a diode and pulse light [12].

Previously, our research group had developed a light-emitting addressable liquid crystal spatial light modulator with a high damage threshold, which has been used in several laser systems to realize beam pre-shielding $[13,14]$, homogenization, and other functions [13]. Recently, the damage threshold of this device can reach $521 \mathrm{~mJ} / \mathrm{cm}^{2}$. Based on this, we designed a 3D additive manufacturing scheme for SE technology and verified the feasibility of the scheme using tin material and a pulse light source with a pulse full width at half maximum of $8 \mathrm{~ns}$. The resolution of the formed metal was also analyzed. 


\section{System Design of 3D Additive Manufacturing Scheme of SE}

The principle of the SE AM is to print layer-by-layer. When irradiated by a single-pulse laser, the powder on the actual layer is melted. After that, the powder is laid again by the scraper, and the metal powder is melted and formed after being irradiated by the other laser pulse. This step is repeated continuously until the entire sample is formed. In this section, we mainly focus on the construction of the entire optical system used for the SE technology. As shown in Figure 1, the optical system is composed of a short-pulse laser, an optical transmission system, an optically-addressed spatial light modulator (OASLM), and a vacuum tube. The short-pulse laser was provided by Keamtech (China), and it had a wavelength of $1064 \mathrm{~nm}$, full width at half maximum of $8 \mathrm{~ns}$, frequency in the range of $1-10 \mathrm{~Hz}$, and a nearly flat top output laser beam profile. The laser was expanded to $27 \mathrm{~mm}\left(1 / \mathrm{e}^{2}\right)$ through a pair of concave-convex lenses. Then, it was transmitted through a soft-edge aperture to meet the optical aperture of OASLM, which is $22 \mathrm{~mm} \times 22 \mathrm{~mm}$. Finally, the lens pair and mirror relayed the modulated beam to the printing plane. Lenses with different focal lengths can be used to achieve different beam-reduction ratios. In this experiment, the expansion ratios were 3 . A vacuum tube without a pinhole filter was used to prevent air breakdown due to the high energy density at the focal point.

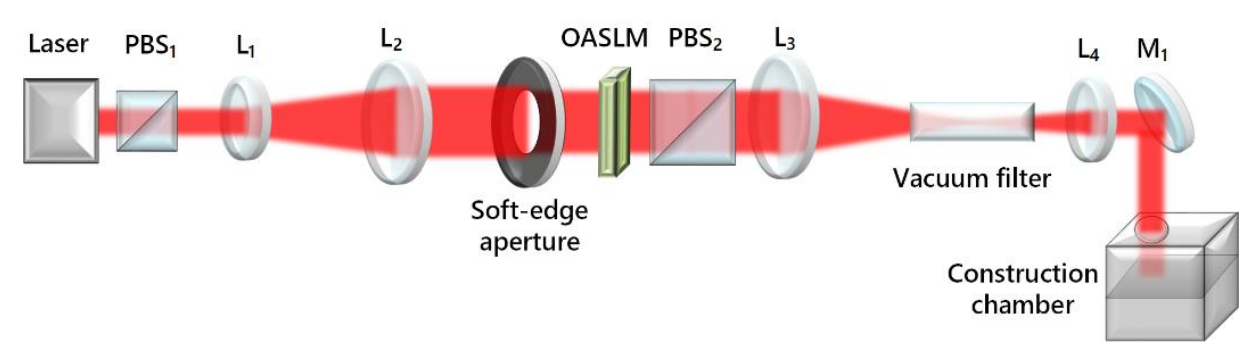

Figure 1. Layout of the optical system of the additive manufacturing scheme of the surface exposure (SE) technology. $\mathrm{PBS}_{1}$, and $\mathrm{PBS}_{2}$ : Polarizing beam splitter; $\mathrm{L}_{1}$ : concave lens; $\mathrm{L}_{2}, \mathrm{~L}_{3}$, and $\mathrm{L}_{4}$ : convex lenses; OASLM: optically addressed spatial light modulator; $\mathrm{M}_{1}$ : mirror.

It is widely known that pure metal powders are easily oxidized in air. During the construction process, the oxidation rate of the pure metal powder is accelerated due to the increase in temperature. Therefore, building a low-oxygen construction chamber is required, as shown in Figure 1. The laser was vertically incident on the internal construction platform from the window above the construction chamber. The entire construction chamber was filled with argon having a purity of $99.99 \%$ to reduce the oxygen content in the construction chamber. Sn powder was used in the experiment.

The energy of the incident laser is converted into heat when it reaches the surface of the metal powder. The heat conducted to the adjacent powder results in a temperature rise around the irradiated area, which affects the resolution of the construction samples. For the isotropic material, it can be approximately characterized by the theoretical thermal diffusion length $L=2 \sqrt{\mathrm{D} \tau}$ [15] which is a simplified, where $\mathrm{D}$ is the thermal diffusion coefficient calculated from thermal conductivity, density, and heat capacity [16], and $\tau$ is the laser pulse duration. For a pulse with the full width at half maximum of $8 \mathrm{~ns}$, the thermal diffusion in Sn powder is about $1.5 \mu \mathrm{m}$. Compared with the long pulse, the short pulse laser offers the potential to improving the resolution of printing results.

\section{OASLM Structure}

The structure of the OASLM [17] is shown in Figure 2. It is composed of a photoconductive layer, a transparent electrode layer, an alignment layer, a liquid crystal molecule layer, and a glass substrate. The photoconductive layer was connected to the liquid crystal layer in series, and an AC voltage of approximately $29 \mathrm{~V}$ was applied during operation. When a write-in optical signal (blue, $470 \mathrm{~nm}$ ) is incident on the photoconductive layer, with a change in the resistance of the photoconductive layer, the partial pressure on the 
liquid crystal layer changes, which results in different deflection states of the liquid crystal molecules. When a read-out light signal is incident, its optical parameters change correspondingly [13]. Transmissive OASLM has a high transmittance in the range of $85-90 \%$. Compared with a reflective structure, the transmissive OASLM is more convenient in the construction of optical path.

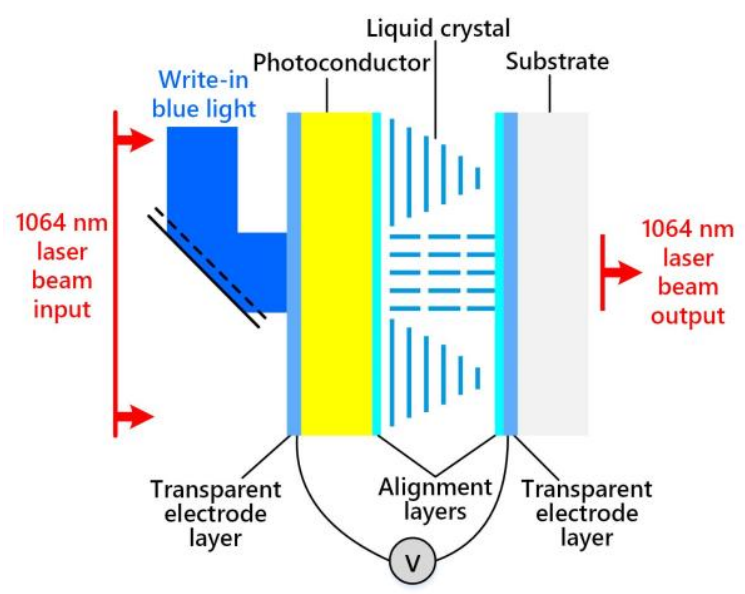

Figure 2. Schematic diagram of the OASLM.

The OASLM can be divided into two types: amplitude type and phase type. When the director difference of the liquid crystal molecule on the front and back surface is $90^{\circ}$, the transmittance of the read-out light signal has a monotonous, nearly linear relationship with the intensity of blue light on the photoconductive layer. When the liquid crystal molecular twist is $0^{\circ}$, the phase delay of the output light varies with the intensity of blue light on the photoconductive layer, which can be used for phase modulation. When using the phase type modulator to realize the intensity modulation, it is usually placed at the front focus of the lens. In this way, the intensity distribution of the output light after lens or the intensity distribution after the phase type modulator and then the far-field transmission can be realized by loading the phase hologram on the modulator, and the phase hologram should be calculated by Fourier transform [18]. In addition, Marquez has reported that the Fourier transform is in need to using the phase type modulator [19]. However, the amplitude modulator can be directly loaded with an optical signal for the corresponding modulation, which is more convenient to operate.

The device was integrated into a volume of $90 \mathrm{~mm} \times 74 \mathrm{~mm} \times 134 \mathrm{~mm}$, and the aperture was $22 \mathrm{~mm} \times 22 \mathrm{~mm}$. The damage threshold of the OASLM was tested to be $521 \mathrm{~mJ} / \mathrm{cm}^{2}$ (@ $1064 \mathrm{~nm}, 4 \mathrm{~ns}$ ) using the N-on-1 method.

\section{Requirement Analysis of Laser Energy Density for Surface Irradiated Tin Laser Additive Fabrication}

The melting threshold of tin was simulated using a finite-element method. The dimensions of the powder were $34 \times 20 \times 1 \mathrm{~mm}^{3}$, and the laser was irradiated at the center of the powder. Owing to the symmetrical nature of the problem, we established a $1 / 4$ model $\left(17 \times 10 \times 1 \mathrm{~mm}^{3}\right)$. The 3D heat conduction model can be expressed as:

$$
\rho C_{p} \frac{\partial T}{\partial t}+\nabla \cdot(-k \nabla T)=Q
$$

where $\rho, C_{p}$, and $k$ are the density, specific heat capacity, and thermal conductivity, respectively, and $Q$ is the input source, which is the pulsed laser incident along the $z$-axis. Benchmarking the experiment, the input source had a uniform heat flux and the time domain obeys a Gaussian distribution with full width at half maximum of $8 \mathrm{~ns}$. The beam waist radius was $0.42 \mathrm{~mm}$. The absorption coefficient of material at $1064 \mathrm{~nm}$ was set to be 
0.2. The initial temperature was $100{ }^{\circ} \mathrm{C}$. In addition, it was assumed that the heat source was focused on center of the model and there was no radiant heat loss or melting.

The powder layer is a mixture of solid (Sn) and gas (air) phases. Theoretically, in additive manufacturing processes, the powder layer has a discrete powder particle structure with a single point connection; actually, the connection between adjacent powders typically has the shape of the thin neck rather than a single point. Hence, the thermophysical parameters of the powder are very different from those of the bulk material. Here, a linear scaling approach is adopted to describe the thermal properties of the powder bed, and the effective density, specific heat capacity, and thermal conductivity of the powder are given as follows [20]:

$$
\begin{gathered}
\rho=\varphi \rho_{\text {air }}+(1-\varphi) \rho_{s} \\
C_{p}=\frac{1}{\rho}\left(\varphi \rho_{\text {air }} C_{p, \text { air }}+(1-\varphi) \rho_{s} C_{p, s}\right) \\
k=(1-\varphi)^{2} k_{s}
\end{gathered}
$$

where $\varphi$ is the initial packing porosity, defined as the fraction of voids with respect to the bulk material, $\rho_{s}, C_{p, s}$, and $k_{s}$ are the density, specific heat capacity, and thermal conductivity of the bulk material, respectively, and $\rho_{a i r}$ and $C_{p, a i r}$ are the density and heat capacity of air, respectively, as shown in Table 1.

Table 1. Thermal properties of Sn and air.

\begin{tabular}{cc}
\hline Thermal Property & Value \\
\hline Bulk Sn density $\left(\rho_{s}\right)$ & $7280 \mathrm{~kg} / \mathrm{m}^{3}$ \\
Bulk Sn specific heat capacity $\left(C_{p, s}\right)$ & $200 \mathrm{~J} / \mathrm{kg} \cdot \mathrm{K}$ \\
Bulk Sn thermal conductivity $\left(k_{s}\right)$ & $60 \mathrm{~W} / \mathrm{m} \cdot \mathrm{K}$ \\
Air density $\left(\rho_{\text {air }}\right)$ & $1.2 \mathrm{~kg} / \mathrm{m}^{3}$ \\
Air specific heat capacity $\left(C_{p, \text { air }}\right)$ & $1 \mathrm{~kJ} / \mathrm{kg} \cdot \mathrm{K}$ \\
\hline
\end{tabular}

Figure 3a shows surface temperature under the laser irradiation with different energy density. The higher the energy density of incident laser, the higher the temperature of laser irradiated surface. It can be seen that when the laser energy density was irradiated once with a laser energy of $0.88 \mathrm{~J} / \mathrm{cm}^{2}$, the temperature of the powder layer reached the melting point of tin $\left(231.9^{\circ} \mathrm{C}\right)$. The surface temperature of the powder when the laser was incident of $0.88 \mathrm{~J} / \mathrm{cm}^{2}$ is shown in Figure $3 \mathrm{~b}, \mathrm{c}$. The temperature reached the melting point in the laser irradiation range, while for the other areas, the temperature is lower than the melting point, which could improve the resolution of melting. Therefore, a laser energy density of more than $0.88 \mathrm{~J} / \mathrm{cm}^{2}$ was required to melt the powder in the experiment.

(a)

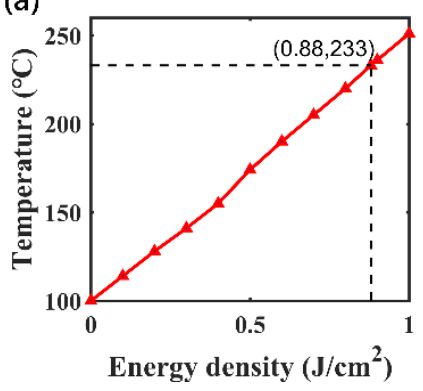

(b)

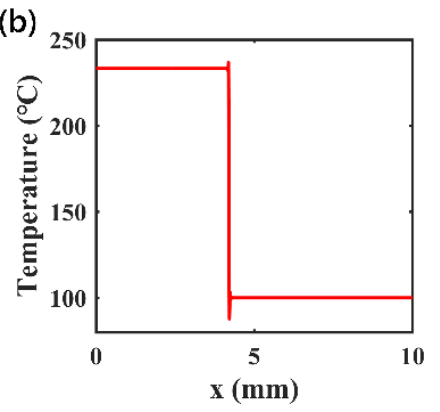

(c)

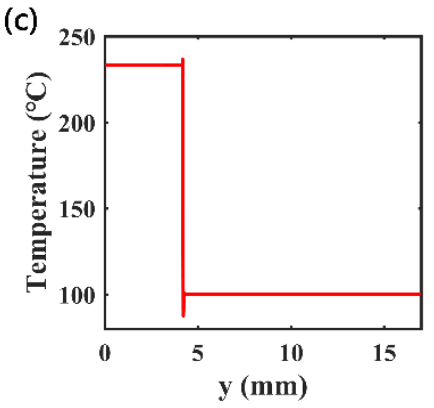

Figure 3. Finite-element simulation results. (a) Surface temperature under the laser irradiation with different energy density. (b) Temperature in the $x$-direction. (c) Temperature in the y-direction.

\section{Experiments of SE Metal Additive Manufacturing Based on OASLM}

To verify whether SE AM can be realized using the method described above, tin powder with a low melting point was used. As pure metal powder is easily oxidized in air, a chamber filled with argon was constructed. First, the substrate was preheated to 
approximately $100{ }^{\circ} \mathrm{C}$ in advance to improve the laser absorption of the powder, and then the powder was manually laid on the construction platform with the size of $34 \times 20 \mathrm{~mm}^{2}$. To ensure sufficient powder content during melting, the thickness of the powder was approximately $3 \mathrm{~mm}$. The frequency of the laser was $1 \mathrm{~Hz}$. Each time the laser was triggered, the powder was melted in a set pattern.

The melting effect of tin powder was analyzed under different laser energy densities without the application of the OASLM. Based on the simulation results, different energy densities higher than $0.88 \mathrm{~J} / \mathrm{cm}^{2}$ were used to irradiate the surface powder. The surface topology analysis of build samples was conducted with scanning election microscope (SEM). Figure 4 shows top-view SEM images of build samples for different laser energy density. According to SEM observations, the surface open porosity was obvious because of the weak bonding and partially melted powder adhering in Figure $4 a-c$. An increase of energy density of $1.24 \mathrm{~J} / \mathrm{cm}^{2}$ and $1.25 \mathrm{~J} / \mathrm{cm}^{2}$ in Figure $4 \mathrm{~b}, \mathrm{c}$, the effect was a little better than Figure $4 a$, but there was still some failed bonding. Figure $4 d-g$ show a better surface after applying a higher energy density. The surface looked much smoother in Figure $4 \mathrm{e}-\mathrm{g}$. Although there were some small bumps in Figure $4 \mathrm{~d}$, it was relatively flat. In addition, the three-dimensional microscopy was used to test the surface roughness of samples.
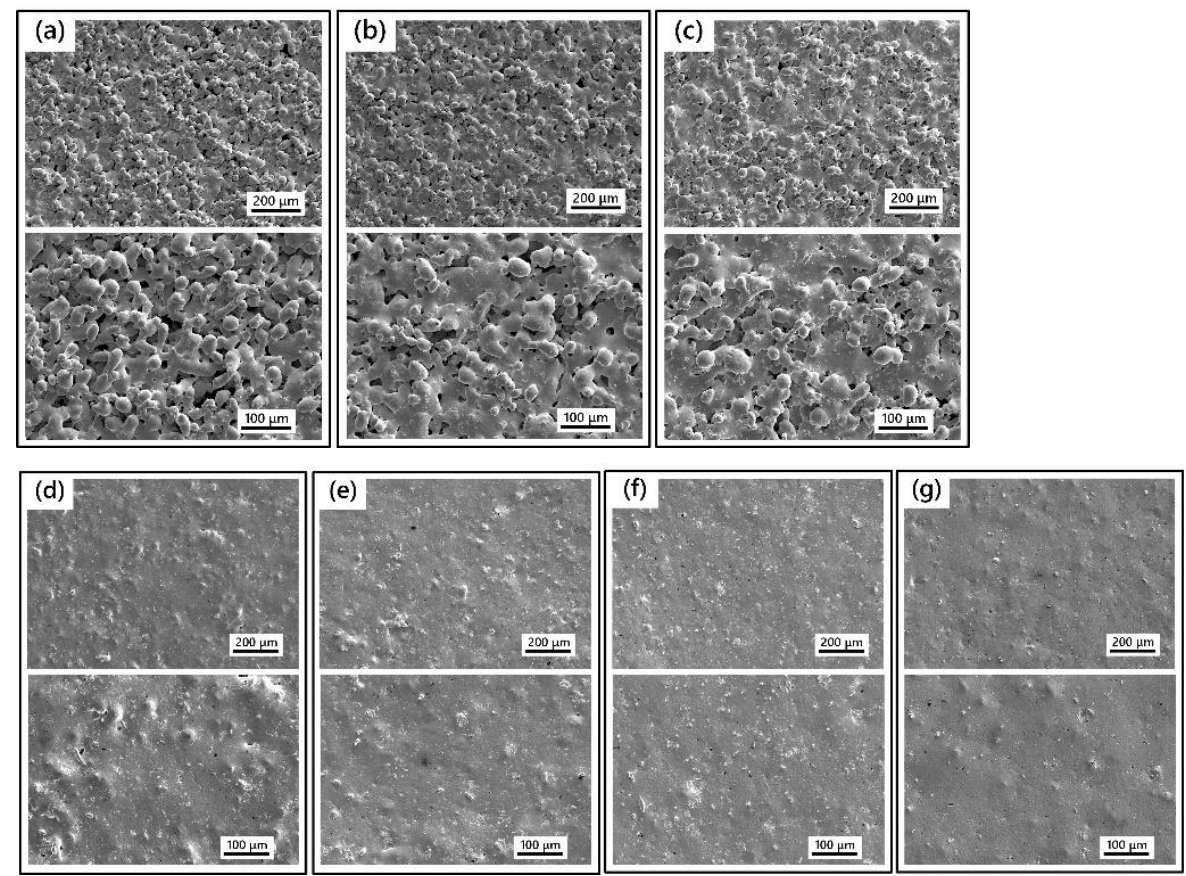

Figure 4. SEM images of melting effect of tin powder with different laser energy densities. The energy densities from $(\mathbf{a}-\mathbf{g})$ are $1.19,1.24,1.25,1.30,1.32,1.35$, and $1.37 \mathrm{~J} / \mathrm{cm}^{2}$.

Figure $5 a, b$ show the surface roughness and the surface height maps with different energy density respectively (i.e., $S_{a}$ roughness, see ISO 25,178 [21] standard) [22]. As either fluence was increased, the surface became smoother. When the energy density was $1.35 \mathrm{~J} / \mathrm{cm}^{2}$ and $1.37 \mathrm{~J} / \mathrm{cm}^{2}$, the hills and valleys for the particles became less distinct. Although there were some fluctuations in Figure 5a, the overall trend of surface roughness decreased with the increase of fluence. As a result, the effect of metal melting forming was better under a higher energy density.

Then, the OASLM was used in the experiment. The energy density irradiating the surface of the metal powder was set to approximately $1.28 \mathrm{~J} / \mathrm{cm}^{2}$. Figure $6 \mathrm{a}-\mathrm{d}$, Figure $6 \mathrm{e}-\mathrm{h}$, Figure 6i-l show the pictures loaded on the OASLM, the corresponding printing results, and the printing results separated from the construction platform, respectively. The patterns were loaded into the complex pattern in turns. First, the word “光” was loaded on the OASLM. As shown in Figure 6e-l, the powder was well formed and could be peeled off 
the construction platform. Then, more complex images were loaded on the OASLM, as shown in Figure $6 \mathrm{~b}-\mathrm{d}$. In Figure $6 \mathrm{k}$, there are some misplaced when the printing results were separated from the construction platform by hand due to each letter of "SIOM" was independent of each other. From the results, we can see that the modulation from simple to complex pictures was well formed. Therefore, SE technology, a new laser AM method, can be realized by modulating the beam using the OASLM.

(a)
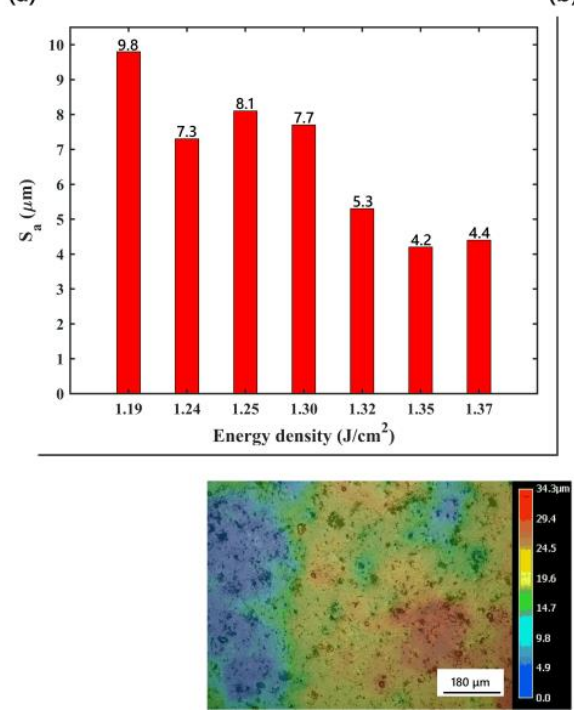

(b)
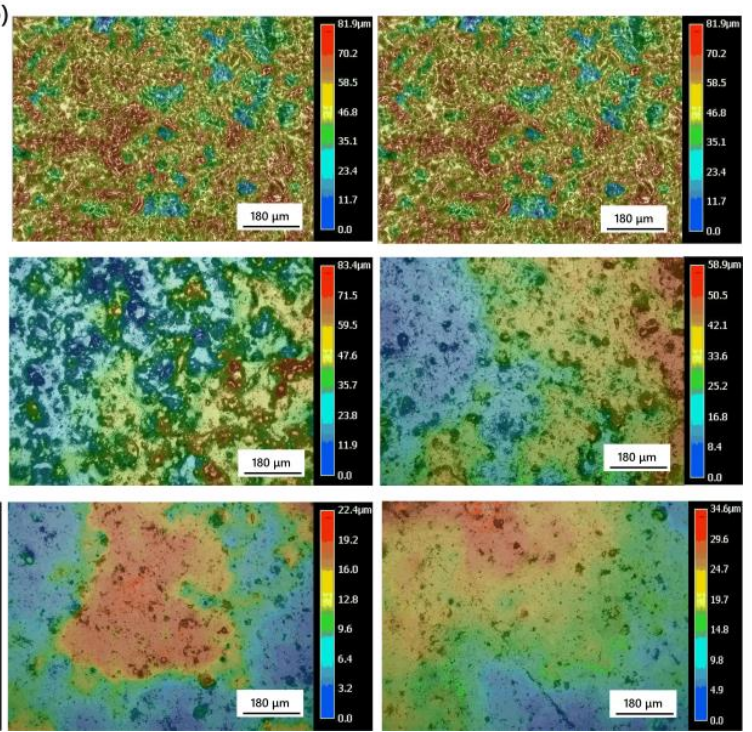

Figure 5. (a) The surface roughness $\left(S_{a}\right)$ of printing samples. (b) Surface height maps with different laser energy densities. The energy densities from the first map to the last map are 1.19, 1.24, 1.25, $1.30,1.32,1.35$, and $1.37 \mathrm{~J} / \mathrm{cm}^{2}$.
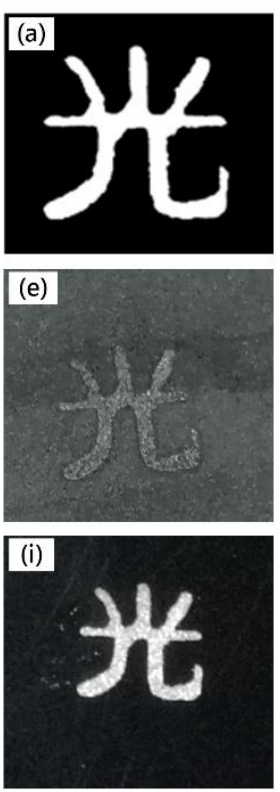
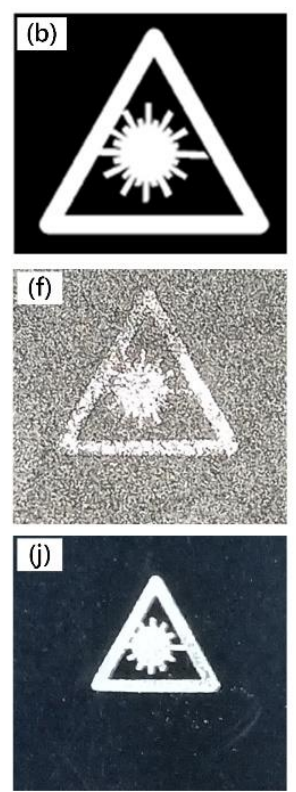
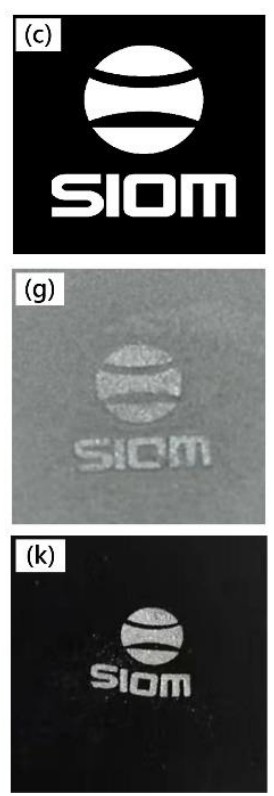
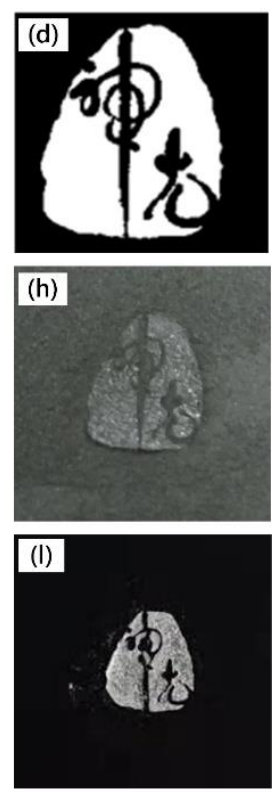

Figure 6. (a-d) Loading images on the OASLM. (e-h) Printing results. (i-l) Printing results separated from the construction platform.

A resolution pattern image was loaded on the OASLM to analyze the resolution of the forming samples in this system, as shown in Figure 7a. Figure $7 \mathrm{~b}$ shows the microscope images of forming resolution sample. It can be seen that the printing results in the red box were essentially the same as the shape of resolution plate, so it can be concluded that the resolution of metal formation in this system was about $100 \mu \mathrm{m}$. In this system, the limit 
factors of resolution of this system are the OASLM with the resolution of $50 \mu \mathrm{m}$ and the particle size of powder. But there are errors caused by the offset of the image plane, and the surface flatness of laying the powder on the construction platform. These errors will be optimized to improve the resolution in subsequent studies.
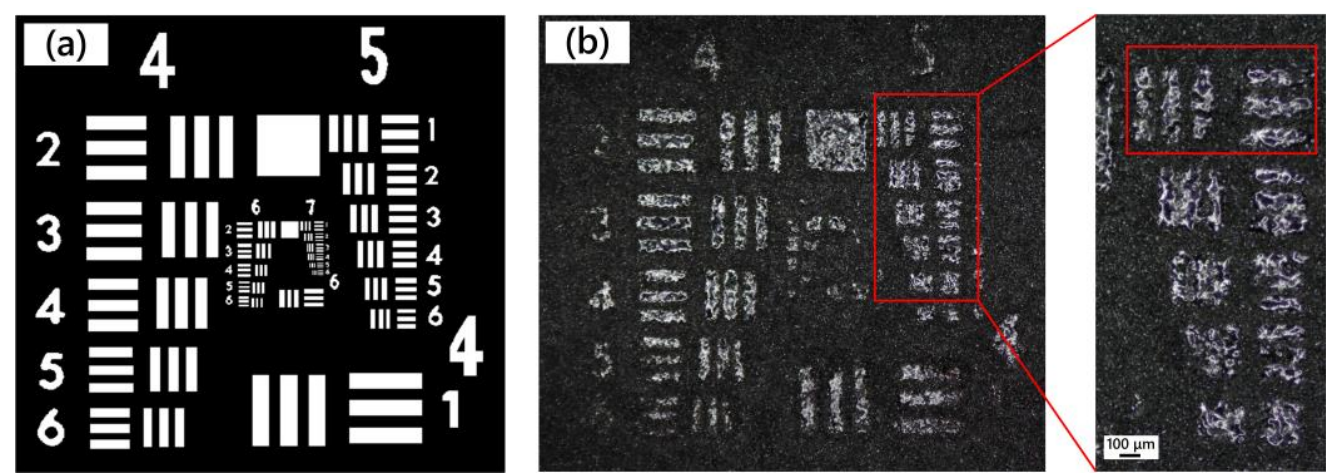

Figure 7. (a) Resolution pattern image loaded on the OASLM. (b) The printing results of the resolution pattern image.

\section{Conclusions}

In this study, we designed a nanosecond pulse laser optical system that can realize SE AM using an OASLM with a high damage threshold of $521 \mathrm{~mJ} / \mathrm{cm}^{2}$. The melting effect of tin powder under different laser energy densities was studied, and a melting experiment was performed with a laser energy density of $1.28 \mathrm{~J} / \mathrm{cm}^{2}$ irradiating the surface of the metal powder. The results show that SE AM can be realized using OASLM to modulate beams with different complexities. The minimum resolution of the entire optical system was approximately $100 \mu \mathrm{m}$. In the future, we aim to improve the powder-spreading system, which is expected to be able to achieve stereostructure printing of metallic materials. Also, we are developing a high damage threshold $\left(>1 \mathrm{~J} / \mathrm{cm}^{2}\right)$ OASLM, which can be used in other metal SE AM applications.

Author Contributions: Conceptualization, W.F. and D.H.; methodology, W.F. and D.H. and Y.C. and H.C.; software, Y.C. and G.X.; validation, Y.C., H.C. and G.X.; formal analysis, Y.C.; investigation, W.F. and D.H. and Y.C.; resources, W.F. and D.H. and H.C. and G.X.; data curation, Y.C.; writing-original draft preparation, Y.C.; writing-review and editing, W.F. and D.H.; supervision, W.F. and D.H.; project administration, W.F. and D.H.; funding acquisition, W.F. All authors have read and agreed to the published version of the manuscript.

Funding: This research was funded by the Strategic Priority Research Program of the Chinese Academy of Sciences, grant number XDA25020303.

Institutional Review Board Statement: Not applicable.

Informed Consent Statement: Not applicable.

Data Availability Statement: Not applicable.

Acknowledgments: We acknowledge the financial support of Self Deployed Projects of Shanghai Institute of Optics and Fine Mechanics, Chinese Academy of Sciences.

Conflicts of Interest: The authors declare no conflict of interest.

\section{References}

1. Stoebenau, S.; Bentley, J.L.; Ferralli, I.; Brunelle, M.J.; Medicus, K.; Whitsitt, R. Current use and potential of additive manufacturing for optical applications. In Proceedings of the Optifab Conference, Rochester, NY, USA, 16-19 October 2017.

2. Sercombe, T.B.; Schaffer, G.B. Rapid manufacturing of aluminum components. Science 2003, 301, 1225-1227. [CrossRef] [PubMed]

3. Sun, M.; Miyamoto, I.; Lu, L.; Lu, Y.F.; Sugioka, K.; Fuh, J.Y.H.; Dubowski, J.J. Microstructure and properties of Fe-base alloy fabricated using selective laser melting. In Proceedings of the Second International Symposium on Laser Precision Microfabrication, Singapore, 16-18 May 2001; Volume 4426, pp. 139-142. 
4. AlMangour, B.; Grzesiak, D.; Yang, J.-M. Scanning strategies for texture and anisotropy tailoring during selective laser melting of TiC/316L stainless steel nanocomposites. J. Alloy. Compd. 2017, 728, 424-435. [CrossRef]

5. Harun, W.S.W.; Manam, N.S.; Kamariah, M.S.I.N.; Sharif, S.; Zulkifly, A.H.; Ahmad, I.; Miura, H. A review of powdered additive manufacturing techniques for Ti-6al-4v biomedical applications. Powder Technol. 2018. [CrossRef]

6. Ngo, T.D.; Kashani, A.; Imbalzano, G.; Nguyen, K.T.Q.; Hui, D. Additive manufacturing (3D printing): A review of materials, methods, applications and challenges. Compos. Part B Eng. 2018, 143, 172-196. [CrossRef]

7. Lin, W.; Chen, D.; Chen, S.-C. Emerging micro-additive manufacturing technologies enabled by novel optical methods. Photonics Res. 2020, 8, 1827-1842. [CrossRef]

8. Gan, Z.; Cao, Y.; Evans, R.A.; Gu, M. Three-dimensional deep sub-diffraction optical beam lithography with $9 \mathrm{~nm}$ feature size. Nat. Commun. 2013, 4, 2061. [CrossRef]

9. Baghjari, S.H.; Akbari Mousavi, S.A.A. Effects of pulsed Nd:YAG laser welding parameters and subsequent post-weld heat treatment on microstructure and hardness of AISI 420 stainless steel. Mater. Des. 2013, 43, 1-9. [CrossRef]

10. Chludzinski, M.; dos Santos, R.E.; Churiaque, C.; Fernández-Vidal, S.R.; Ortega-Iguña, M.; Sánchez-Amaya, J.M. Pulsed laser butt welding of AISI 1005 steel thin plates. Opt. Laser Technol. 2021, 134. [CrossRef]

11. Ventrella, V.A.; Berretta, J.R.; de Rossi, W. Pulsed Nd:YAG laser seam welding of AISI 316L stainless steel thin foils. J. Mater. Process. Technol. 2010, 210, 1838-1843. [CrossRef]

12. Matthews, M.J.; Guss, G.; Drachenberg, D.R.; Demuth, J.A.; Heebner, J.E.; Duoss, E.B.; Kuntz, J.D.; Spadaccini, C.M. Diode-based additive manufacturing of metals using an optically-addressable light valve. Opt. Express 2017, 25, 11788-11800. [CrossRef] [PubMed]

13. Huang, D. Key Techniques of Near-Field Beam Quality Control in High Power Laser; University of Chinese Academy of Sciences: Shanghai, China, 2013.

14. Huang, D.; Fan, W.; Li, X.; Lin, Z. Performance of an optically addressed liquid crystal light valve and its application in optics damage protection. Chin. Opt. Lett. 2013, 11, 072301-072305. [CrossRef]

15. Finn, D.S.; Lin, Z.; Kleinert, J.; Darwin, M.J.; Zhang, H. Study of die break strength and heat-affected zone for laser processing of thin silicon wafers. J. Laser Appl. 2015, 27, 032004. [CrossRef]

16. Miller, J.E.; McDaniel, A.H.; Allendorf, M.D. Considerations in the Design of Materials for Solar-Driven Fuel Production Using Metal-Oxide Thermochemical Cycles. Adv. Energy Mater. 2014, 4, 1300469. [CrossRef]

17. Huang, D.; Fan, W.; Cheng, H.; Wei, H.; Wang, J.; An, H.; Wang, C.; Cheng, Y.; Xia, G.; Li, X.; et al. Applications of OALCLV in the high power laser systems. Proc. SPIE 2017, 10457.

18. Siyuan, L.; Jingyu, Z. Principles and applications of ultrafast laser processing based on spatial light modulators. Laser Optoelectron. Prog. 2020, 57, 111431. [CrossRef]

19. Marquez, A.; Lemmi, C.; Escalera, J.C.; Campos, J.; Ledesma, S.; Davis, J.A.; Yzuel, M.J. amplitude apodizers encoded onto Fresnel lenses implemented on a phase-only spatial light modulator. Appl. Opt. 2001, 40, 2316-2322. [CrossRef]

20. Tran, H.-C.; Lo, Y.-L. Heat transfer simulations of selective laser melting process based on volumetric heat source with powder size consideration. J. Mater. Process. Technol. 2018, 255, 411-425. [CrossRef]

21. ISO 25178-2. Geometrical Product Specifications (GPS)—Surface Texture: Areal-Part 2: Terms, Definitions and Surface Texture Parameters; ISO: Geneva, Switzerland, 2012.

22. Gockel, J.; Sheridan, L.; Koerper, B.; Whip, B. The influence of additive manufacturing processing parameters on surface roughness and fatigue life. Int. J. Fatigue 2019, 124, 380-388. [CrossRef] 